\title{
New Record of the Leech Limnotrachelobdella sinensis Infecting Freshwater Fish from Japanese Waters
}

\author{
Kazuo Ogawa ${ }^{1 *}$, Olga Rusinek ${ }^{2}$ and Masaharu Tanaka ${ }^{3}$ \\ ${ }^{1}$ Department of Aquatic Bioscience, Graduate School of Agricultural and Life Sciences, \\ The University of Tokyo, Bunkyo, Tokyo 113-8657, Japan \\ ${ }^{2}$ Baikal Museum of the Siberian Branch of the Russian Academy of Sciences, \\ Listvyanka, 664520, Russia \\ ${ }^{3}$ Aquatic Life Conservation Center, Research Institute of Environment, \\ Agriculture and Fisheries, Osaka Prefectural Government, \\ Neyagawa, Osaka 052-0088, Japan
}

(Received January 10, 2007)

\begin{abstract}
A hitherto unknown leech has been found infected on crucian carps Carassius auratus langsdorfii and C. cuvieri in the Yodo River system since 2000. From the morphological characteristics, the parasite was identified as Limnotrachelobdella sinensis (Piscicolidae). Parasitological surveys on 16 species of wild fish $(n=1,661)$ caught from October 2000 until March 2005 revealed that the leech was found only from moribund crucian carps. It has a one-year life cycle, in which the leeches were found from December until April next year. Because of its recovery only from moribund fish, large size (up to $4.9 \mathrm{~cm}$ in body length) and frequent heavy infection (highest number of parasites/fish: 62), its pathological effects on the hosts were suspected. However, such effects were not made clear except for the hemorrhages and erosion on and near the inner surface of operculum, the attachment site. This is the first record of this parasite from Japanese waters. Since the geographical distribution of the leech in Japan is still restricted to the Yodo River system, the potential risk of spread of the parasite to other water bodies is discussed.
\end{abstract}

Key words: Limnotrachelobdella sinensis, Carassius auratus langsdorfii, Carassius cuvieri, leech, crucian carp

A hitherto unknown leech was found infecting the inner operculum of a Japanese crucian carp, Carassius auratus langsdorfii (Japanese name: gin-buna) in the Yodo River system, Osaka Prefecture in January 2000. Next year, another crucian carp, Carassius cuvieri (Japanese name: gengorou-buna) was also found infected. Since then, the leech infection has been confirmed on the two species of fish in the Yodo River system every year. This paper deals with the description and identification of the parasite, with some notes on the host specificity and seasonality in the infection.

\section{Materials and Methods}

Wild fish samplings biweekly from October 2000 to June 2001 and from November 2001 to March 2002, and

\footnotetext{
* Corresponding author

E-mail: aogawak@mail.ecc.u-tokyo.ac.jp
}

monthly from April 2002 to March 2005 were conducted in the Yodo River system at Moriguchi, Osaka Prefecture. A total of 1,542 fish were collected by a casting net. Most of the fish belonged to the family Cyprinidae and the scientific names of the fishes examined follow those used by Nakabo (1993): oikawa Zacco platypus $(\mathrm{n}=701)$, kouraimoroko Squalidus chankaensis $(n=502)$, hasu Opsariichthys uncirostris uncirostris $(n=211)$, kamatsuka Pseudogobio esocinus esocinus $(n=46)$, nigoi Hemibarbus barbus $(n=35)$, motsugo Pseudorasbora parva $(n=15)$, gengorou-buna Carassius cuvieri $(\mathrm{n}=7)$, gin-buna Carassius auratus langsdorfii $(n=5)$, zezera Biwia zezera $(n=3)$, common carp Cyprinus carpio $(\mathrm{n}=2)$, "tabira" Acheiolognatus sp. $(\mathrm{n}=$ 2). Other groups of fish examined included largemouth bass Micropterus salmoides (Centrachidae) $(n=4)$, bluegill Lepomis macrochirus (Centrachidae) $(n=4)$, numachichibu Tridentiger brevispinis (Gobiidae) $(\mathrm{n}=3)$, "yoshinobori" Rhinogobius sp. (Gobiidae) $(n=1)$ and ayu Plecoglossus altivelis (Plecoglossidae) $(n=1)$. 
Besides, moribund fish, mostly crucian carps, $C$. cuvieri (5.7-32.2 cm in body length, 5.7-991 $\mathrm{g}$ in body weight; $\mathrm{n}=65)$ and $C$. auratus langsdorfii $(9.3-33.5 \mathrm{~cm}$ in body length, 28-1,300 $\mathrm{g}$ in body weight; $\mathrm{n}=54$ ), were also sampled by a scoop net whenever available during the period from January 2000 to March 2005. All the fish were macroscopically examined for the presence of the leech. Water temperature near the sampling site fluctuated between $3.7^{\circ} \mathrm{C}$ and $31.0^{\circ} \mathrm{C}$ in $2000-04$.

Some of the leeches were fixed in $10 \%$ formalin for measurement and identification. They were investigated under the instruction of Lukin (1976). Figures were drawn with the aid of a camera lucida.

\section{Results}

Description and identification of the parasite (Fig. 1)

Host: Carassius auratus langsdorfii Cuvier \&

Valenciennes and Carassius cuvieri Temminck \&

Schlegel (Cyprinidae, Cypriniformis).

Localities: Yodo River (Moriguchi City, Osaka; 34² $75^{\prime} \mathrm{N}$, 13557’E)

Site: Inner operculum.

Date: March 5, 2001.

Material: Deposited in the collection of Baikal Museum of the Siberian Branch of the Russian Academy of Sciences, Irkutsk, Russia $(n=5)$.

Description: The body is distinctly divided into a relatively short, narrower neck and a long, broad trunk. The trunk is broader and longer than the neck by a factor of 3 and 5, respectively. The body is 3.8-4.9 $\mathrm{cm}$ (average $4.30 \mathrm{~cm}$ ) in length and $0.9-1.5 \mathrm{~cm}$ (aver-
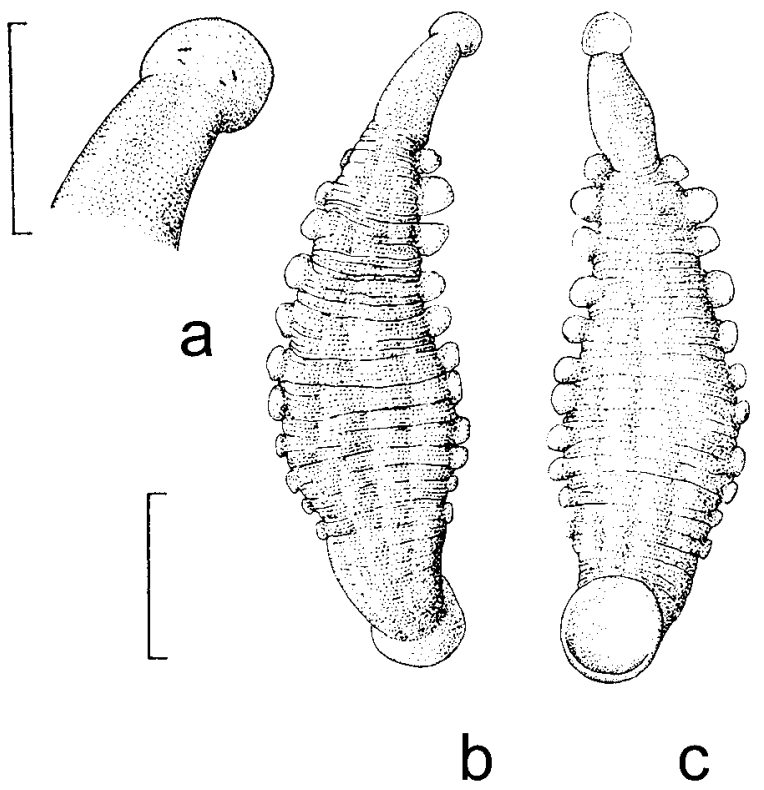

C

Fig. 1. Drawings of Limnotrachelobdella sinensis. a, anterior end; b and c, entire body, dorsal and ventral view, respectively. Scales: $0.5 \mathrm{~cm}$ for $\mathrm{a} ; 1 \mathrm{~cm}$ for $\mathrm{b}$ and $\mathrm{c}$. age $1.14 \mathrm{~cm}$ ) in width. The anterior sucker is relatively small, and its diameter is by a factor of 3-4 less than that of the posterior sucker. The posterior sucker is markedly broader than the end of the body. Eyes are in two pairs, but one of the five specimens examined has no eyes. Bubble-like protrusions on body sides occur in 11 pairs, spherical and large. They impart this leech an intrinsic shape of its body. The first pair (most anterior pair) of protrusions are smaller than the second one, and the size decreased from the second to the last pair.

\section{Infection among fish collected}

The leech attached to the inner surface of the operculum (Fig. 2), and less frequently to the other parts of the body like the mouth lips and eyes. The gills were anemic and the inner surface of the operculum showed extensive hemorrhages and erosion.

No fish sampled by a casting net from October 2000 until March 2005 was infected ( $n=1,542)$. Moribund crucian carps (C. auratus langsdorfii and $C$. cuvieri) occasionally sampled by a scoop net were found infected with the leech. Prevalence of infection and parasite abundance (number of parasites/number of fish examined) in these moribund fish were $79.8 \%$ (95/119) and 8.0 , respectively, with the highest number/fish being 62 recorded from $C$. auratus langsdorfii in December 2001. No clear relationship was recognized between the number of parasites and fish size. The parasite tended to grow from December until March (Fig. 3). Measurements of the body length were: 12-24 mm (mean: $18.3 \mathrm{~mm} ; \mathrm{n}=42$ ) in December 17, 2001; 18-25 mm (mean: $21.1 \mathrm{~mm} ; \mathrm{n}=9$ ) in February 7, 2001; 33-49 $\mathrm{mm}$ (mean: $41.5 \mathrm{~mm} ; \mathrm{n}=8$ ) in March 5, 2001, and 28 $\mathrm{mm}$ and $32 \mathrm{~mm}$ (mean: $30.0 \mathrm{~mm} ; \mathrm{n}=2$ ) in March 21, 2001.

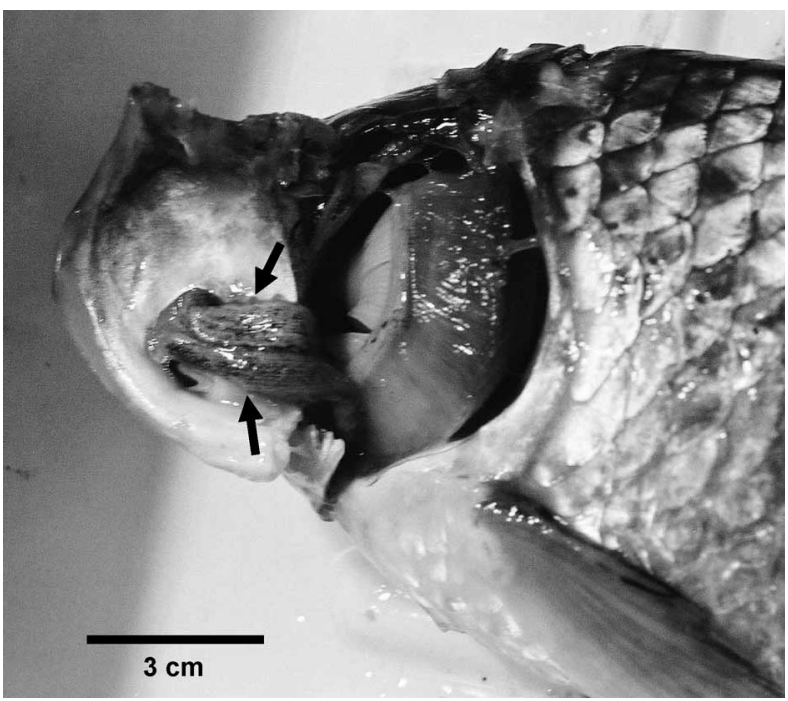

Fig. 2. Two leeches (arrows) attaching to the operculum of crucian carp. Scale bar: $3 \mathrm{~cm}$. 


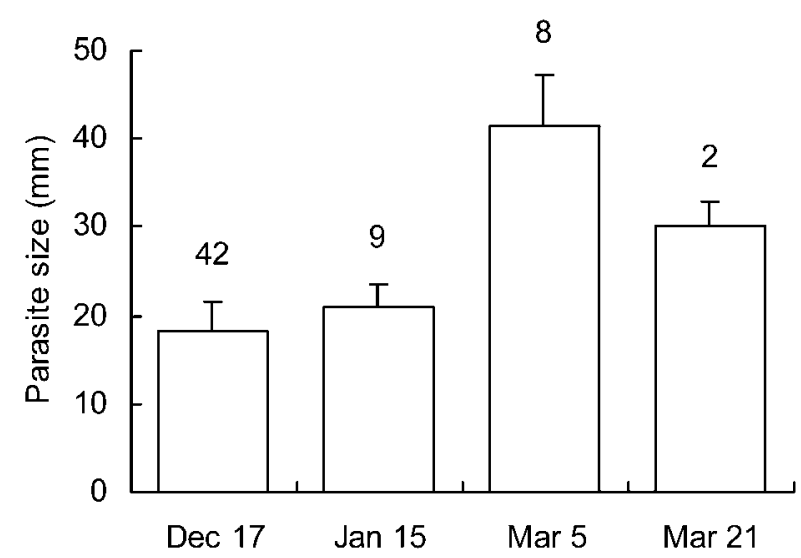

Fig. 3. Growth of Limnotrachelobdella sinensis. Numbers above the bars represent the number of specimens measured.

Among the other 14 species of fish examined $(\mathrm{n}=$ 1,530), five cyprinids ( $Z$. platypus, $S$. chankaensis, $O$. uncirostris uncirostris, $P$. esocinus esocinus and $H$. barbus) were considered unsuitable hosts of this leech, while it was inconclusive whether the remaining nine species of fish were hosts of this leech or not because of the small sample size.

Annual and seasonal occurrences of the leech on crucian carps

Since no clear differences in the prevalence and parasite abundance between the two crucian carps (data not shown), the data on the annual and seasonal occurrences on these fishes were combined. Prevalence was high until 2002, but it suddenly dropped to a very low level in 2003. In 2004-05, the infection level recovered to some extent (Fig. 4). The reason for this annual

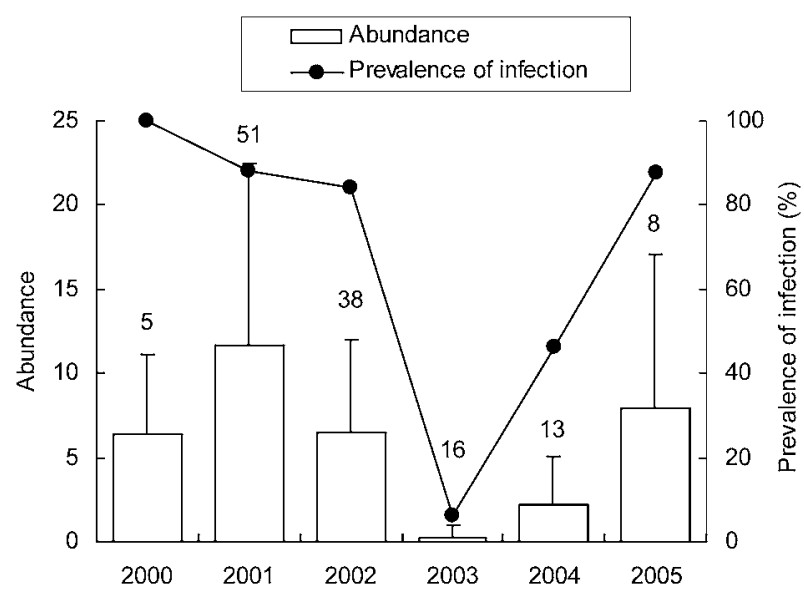

Fig. 4. Annual fluctuation in the infection of crucian carps (Carassius auratus langsdorfii and C. cuvieri) with Limnotrachelobdella sinensis. Data from moribund fish sampled by a scoop net $(n=119)$ and from apparently healthy fish sampled by a casting net $(n=12)$ are combined. Numbers above the bars represent the number of specimens examined.

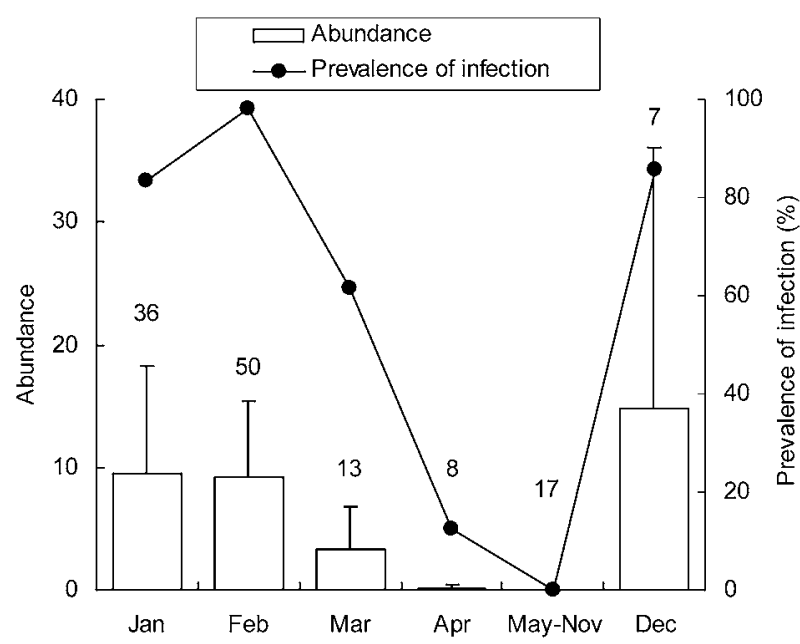

Fig. 5. Seasonal fluctuation in the infection of crucian carps (Carassius auratus langsdorfii and C. cuvieri) with Limnotrachelobdella sinensis. Data from moribund fish sampled by a scoop net $(n=119)$ and from apparently healthy fish sampled by a casting net $(n=12)$ are combined. Numbers above the bars represent the number of specimens examined.

fluctuation in the infection is unknown. There was a clear seasonality in the occurrence of the parasite: the prevalence of infection of crucian carps was high during December through March, while no infection was recorded from May through November (Fig. 5). This suggests that the leech infected crucian carps in December, grew and matured in the following months, and left the hosts by April.

\section{Discussion}

Five species are known in the genus Limnotrachelobdella: L. sinensis, L. turkestanica, $L$. okae, L. taimeni and L. fujianensis (Lukin; 1976; Yang, 1987). Among them, $L$. sinensis, $L$. turkestanica and $L$. taimeni infect freshwater fish and $L$. okae and $L$. fujianensis infect marine fish. Phylogenetic relationship among these species is not clear. $L$. sinensis can be differentiated from the other species of the genus mainly by the number, shape and size of the bubble-shaped lateral protrusions.

L. sinensis was first recorded in China; Blanchard (1896) described Trachelobdella sinensis $n$. sp. (now $L$. sinensis) from Chinese carp (scientific name not given) in Chefoo (=Yantai), Shandon Province. According to Yang (1987), this leech was reported from carp Cyprinus carpio and crucian carp (scientific name not given) in Anhui, Jiangsu, Hunan and Heilongjiang Province. Outside China, $L$. sinensis was recorded on Amur carp Cyprinus carpio haematopterus and Prussian carp Carassius auratus gibelio in Lake Khanka and the Amur River from Blagoveshchensk to Khabarovsk, Russia (Epstein, 1987; Golovina, 2003) and on Cyprinus carpio 
nudus (=Cyprinus carpio) from Kangwondo, Korea (Rhee, 1986). In Japan, Oka (1910) reported T. sinensis from the coast of Tokyo Bay, Awa, Sagami and Kaga (host unspecified). However, Moore (1924) revealed differences in morphology and habitat between Oka's description and the original description by Blanchard (1896) and proposed a new name, T. okae (now Limnotrachelobdella okae), for Oka's specimens. Thus, the leech has been recorded from the Far East except Japan.

Assuming $L$. sinensis is an indigenous parasite of fishes in the Yodo River system, it means that such a big parasite has been overlooked until recently. Besides, no record of this parasite has so far been made on fishes from other water bodies in Japan. Further, no big changes in the environment in and around the Yodo River system, like water temperature or other water quality parameters, have been noticed, which could have promoted a sudden increase of population of any indigenous but unnoticed parasite. Rather, it seems more likely that $L$. sinensis is a recently introduced parasite to the Yodo River system.

Leeches parasitic on fish have been documented as pathogens to hosts (Burreson, 2006). Firstly, fish-parasitic leeches, including $L$. sinensis, feed on blood from hosts. Secondly, attachment by the posterior sucker can cause severe epidermal erosion. Thirdly, leeches may provide portals of entry through their feeding and attachment wounds for secondary pathogens. Further, they may act as vectors of fish pathogens, including viruses, bacteria and haematozoic protists.

In the present study, anemia of infected fish may have been caused by the parasite's blood feeding. However, co-infection with Flavobacterium psychrophilum, the causative agent of bacterial coldwater disease, was often isolated and confirmed by PCR (Yamashita et al., $\left.2003^{*}\right)$. This bacterium is known to cause anemia to infected fish (Nematollahi et al., 2003; Miwa and Nakayasu, 2005), and some crucian carp, free from leech infection, showed severe anemia. Thus, it was not made clear to what extent $L$. sinensis contributed to the observed anemia of crucian carps. The possibility that the leech played as a vector of $F$. psychrophilum was examined by PCR to detect the bacterial gene in the parasite body (M. Tanaka, unpublished data). Negative results for all the leeches examined suggest that $L$. sinensis was not involved in the dissemination of the bacterial coldwater disease among crucian carps in the Yodo River system. However, it is still possible that $L$. sinensis infection provided $F$. psychrophilum with its por-

\footnotetext{
* Yamashita, Y., Y. Minami, T. Nakai and M. Tanaka (2003): Plasmid and phage types of Flavobacterium psychrophilum isolated from ayu and crucian carps. Abstract of Annual Meeting of Japanese Society of Fisheries Science, Tokyo University of Fisheries, Tokyo. p. 101.
}

tals of entry to the fish.

The life cycle of $L$. sinensis is not completely understood. Leeches that feed on fish blood may be either temporary or semi-permanent parasites (Burreson, 2006). Data on the growth of $L$. sinensis from December until March (Fig. 3) suggest that it is categorized into the latter group of leeches, which remain on the host during development. In piscicolid leeches, mating takes place on the host and spermatophores are implanted anywhere on the parasite body. Then, they leave host to lay eggs in small chitinoid cocoons that are attached to water plants and other underwater objects (Lukin, 1976). Newly hatched piscicolid leeches can survive for a week or more before their first blood meal (Burreson, 2006). Earliest detection of L. sinensis was in December, when the smallest specimen measured only $12 \mathrm{~mm}$ in body length. The survival time of hatched leeches and recovery of the smallest leech in December suggest eggs of $L$. sinensis hatch in late autumn or early winter. Thus, it is estimated that $L$. sinensis in the Yodo River system has a one-year life cycle. In China, this leech has a similar seasonal occurrence; it was found on the host only from the end of December until the beginning of June in Chao Hu Lake, Anhui Province (Yang, 1987).

This parasite is known to infect fishes of the genus Carassius and Cyprinus. In this study, two species of crucian carps have been found infected; common carp was not infected, but only two specimens have been examined. It is still possible that $L$. sinensis can infect other Carassius species and common carp distributed in Japanese waters. Since crucian carps and common carp are almost ubiquitous fish in Japanese rivers and lakes, transportation of infected fish from the Yodo River system to elsewhere must be avoided. Once introduced to a new area, it may be very difficult to eradicate this parasite from there.

\section{Acknowledgement}

Fish samplings conducted by Aquatic Life Conservation Center was financially supported by Yodogawa River Office, Ministry of Land, Infrastructure and Transport, Japan.

\section{References}

Blanchard, R. (1896): Description de quelques Hirudinees Asiatiques. Mém. Soc. Zool. Fr., 9, 316-330.

Burreson, E. R. (2006): Phylum Annelida: Hirudinea as vectors and disease agents. In "Fish diseases and disorders. Vol. 1. Protozoan and metazoan infections. 2nd edition" (ed. by P. T. K. Woo). CAB International, Wallingford, pp. 566-591.

Epstein, V. M. (1987): Phylum Annelida. In "Identification key to parasites of freshwater fishes of USSR. Vol. 3. Metazoan parasites. Part 2." (ed. by O. N. Bauer). Akademii 
Nauk SSSR, Leningrad, pp. 340-372. (In Russian).

Golovina, N. A. (2003): Bdellocelosi. In: Ichthyopathology (ed. by N. A. Golovina and O. N. Bauer). Moskow, Mir, pp. 352-356

Lukin, E. I. (1976): Leeches of the fresh- and salt-water basins. In: "Leeches. Fauna of USSR". Leninigrad, Nauka, Vol. 1, pp. 305-315. (In Russian).

Miwa, S. and C. Nakayasu (2005): Pathogenesis of experimentally induced bacterial cold water disease in ayu Plecoglossus altivelis. Dis. Aquat. Org., 67, 93-104.

Moore, J. P. (1924): Notes on some Asiatic leeches (Hirudinea) principally from China, Kashimir, and British India. Proc. Acad. Nat. Sci. Philad., 76, 343-388.

Nakabo, T. (1993): Fishes of Japan with pictorial keys to the species. Tokai Univ. Press, Tokyo, 1,474 p. (In Japanese). Nematollahi, A., A. Decostere, F. Pasmans and F. Haesebrouck (2003): Flavobacterium psychrophilum infections in salmonid fish. J. Fish Dis., 26, 563-574.

Oka, A. (1910): Synopsis der Japaneschen Hirudineen, mit Diagnosen der neuen Species. Annot. Zool. Japon., 7, $165-182$.

Rhee, J.-K. (1986): Trachelobdella sinensis Blanchard, 1896 found from Cyprinus carpio nudus in Korea. Korean $\mathrm{J}$. Parasitol., 24, 216-217. (In Korean with English summary).

Yang, T. (1987): On the genus Limnotrachlobdella Epstein, 1968 and a new species from South China Sea. Acta Hydrobiol. Sin., 11, 268-273. (In Chinese with English summary). 